\title{
LAS TRES SORORES DE RAMÓN J. SENDER: TEORÍA Y PRÁCTICA LITERARIA DEL NUEVO ROMANTICISMO
}

\author{
Jesús Lerate de Castro
}

Una de las cuestiones en las que menos ha reparado la crítica es la enorme influencia que ejercen en la narrativa de Ramón J. Sender (1901-1982) los principios estéticos esbozados por José Díaz Fernández (1898-1940) en su libro El nuevo romanticismo. Bajo este título genérico, se recogen diez ensayos en los que el escritor y periodista salmantino critica duramente la literatura deshumanizada del orteguismo y propugna una nueva sensibilidad artística más acorde con la realidad social del individuo.

Pese al oscuro silencio crítico en el que ha vivido esta obra de Díaz Fernández, El nuevo romanticismo representa un documento clave en el devenir de la novela social española y puede considerarse, con plena justicia, el "manifiesto" literario que guiará los esfuerzos artísticos de una generación de escritores comprometidos como Joaquín Arderius, Julián Zugazagoitia, César Arconada o Ramón J. Sender.

En el caso concreto de este último, la importancia que adquieren los postulados neorrománticos de Díaz Fernández se detecta no sólo en su etapa literaria anterior a la Guerra Civil —en novelas tales como Imán (1930), O.P. (Orden Público) (1931) o Siete domingos rojos (1932)—_ sino también en una obra tan tardía y poco estudiada como Las tres sorores (1974). Este hecho justifica y motiva las páginas que siguen, en las cuales quisiéramos llamar la atención sobre el papel fundamental que juegan los principios estéticos de Díaz Fernández en la praxis literaria de Las tres sorores.

El nuevo romanticismo, también llamado romanticismo revolucionario, aparece en España entre 1927 y 1936 ante la necesidad de crear una nueva forma de entender la vida y el arte. Tiene, por tanto, el mismo propósito que el orteguismo, del que es coetáneo en el tiempo, pero las premisas de las que parte son completamente distintas. En efecto, mientras que José Ortega y Gasset es el inspirador de una corriente literaria elitista, hermética y desvinculada de los problemas sociales; la filosofía estética de Díaz Fernández se sustenta en una concepción humanizada, social y realista del arte. No obstante, habría que hacer una matización en este sentido, ya que si bien es cierto que el neorromanticismo trata de hacer verosímil la realidad, el énfasis no va a ir dirigido tanto hacia el "entendimiento" total de la problemática que se presenta como a suscitar en el lector un instinto, un estado de ánimo concreto. Como el propio Sender señala en el prólogo a Siete domingos rojos: 
Al final del libro, el lector que se haya abandonado lealmente habrá comprendido o no el fenómeno social o político al que me refiero, pero desde luego habrá "sentido" desarrollarse dentro de sí una evidencia nueva. Dirigirse a los sentidos, a la sensibilidad y no al entendimiento, al "intelecto", tiene para mí además la ventaja de que nadie podrá llamarme "intelectual" con plena razón. ${ }^{1}$

Esta interpretación afectiva de la realidad hermana a Sender y al nuevo romanticismo, en general, con el espíritu instintivo, desgarrado e idealista del movimiento que le precedió un siglo antes. Como explica Díaz Fernandez:

Yo no quiero hacer una defensa del romanticismo, al que acuso de hinchazón retórica, de borrachera pasional, de gesticulación excesiva y ociosa. Pero no puedo menos de apreciar en aquella generación arrebatada y triste el anhelo ideal que les ha faltado a las posteriores. $^{2}$

El romántico del siglo XIX entendía la existencia como una confrontación entre el individuo y la sociedad, pero nunca concebía la realidad como una lucha de clases. El héroe romántico, al interiorizar su problemática, se sentía aislado e incapaz de afrontar las trabas y prejuicios sociales que le subyugaban. De ahí, que quisiera evadirse de la realidad, ya fuera física o artísticamente. El escritor neorromantico, por el contrario, no rehuye los conflictos ni contrariedades que se le presentan en la vida, sino que los afronta como paso previo a la transformación de un nuevo orden social. Desde esta perspectiva, la novela del nuevo romanticismo trasciende la temporalidad del momento presente y tiende hacia un futuro en el que se llevará a cabo la armonía de clases, pues "necesitamos vivir para la historia, para las generaciones venideras" $(N R, 48)$. El pasado también le interesa al escritor neorromántico, pero sólo con el propósito de poner de manifiesto que la realidad presente es resultado de unos procesos históricos de los que hay que aprender para evitar que se repitan.

El ideal del nuevo romanticismo es "vincular la literatura y toda la obra intelectual a los problemas que inquietan a las multitudes, porque ellas buscan la justicia" ( $N R, 79-80)$. Por eso, en la narrativa neorromática predominan los temas relacionados con las huelgas, las reivindicaciones laborales, la lucha de clases, etc., pero sin menospreciar otros esencialmente románticos como la libertad, la pasión o el amor, a los que ahora se les imprimirá connotaciones de carácter social.

Influido por el espíritu ideológico de la revolución rusa, el nuevo romanticismo parte del supuesto de que "toda idea es una representación política, una conducta, una concepción en movimiento" (NR, 78). Por eso, entiende que una posición apolítica como la del orteguismo supone una "estafa ideológica" que hay que combatir y erradicar. Para lograr este objetivo, para "hacer un arte para la vida, no una vida para el arte" $(N R, 50)$, Díaz Fernández propone que los intelectuales de izquierda actúen paralelamente al obrerismo revolucionario. Pues un artista que se precie de serlo, dirá el ensayista, "no puede permanecer indiferente a

\footnotetext{
${ }^{1}$ R.J. Sender, Siete domingos rojos (Buenos Aires: Proyección, 1970) 10.

2 J. Díaz Fernández, El nuevo romanticismo (Madrid: Zeus, 1930) 22. En lo sucesivo, las referencias a esta obra se insertan en el texto entre paréntesis, con las iniciales $N R$, y seguidas por el número de página.
} 
los conflictos de la lucha individual o colectiva, ni a las reacciones de tipo humano dentro de la lucha social" $(N R, 82)$.

Según Díaz Fernández, los escritores orteguistas que "permanecen encerrados en sus torres de marfil" evadiendo todo compromiso social, no tienen derecho a llamar a su arte vanguardista. La verdadera vanguardia será "aquélla que ajuste sus formas nuevas de expresión a las nuevas inquietudes del pensamiento" ( $N R, 50)$. Para evitar equívocos, hablará del nuevo romanticismo como "literatura de avanzada" o literatura de vanguardia social, en oposición a la vanguardia estética del orteguismo. Esta "literatura de avanzada" reivindica, como dijimos, una novela social y humanizada, pero sin que vaya en detrimento de su valor artístico. Esta aspiración plantea un problema evidente. ¿Cómo conseguir que el arte trascienda y adquiera una dimensión social, sin recurrir a la retórica hueca que tanto se le critica al romanticismo decimonónico y al orteguismo? Díaz Fernández dirá que "todo arte verdaderamente humano es expresión de un sistema de acción colectiva” (NR, 199-200). Pero también añade que el arte necesita "lírica, color, imagen. . . . [y] por debajo de todo eso, pasión, sinceridad, rebeldía y esfuerzo" $(N R, 81)$. En otras palabras, la retórica se hace imprescindible para expresar los anhelos de la colectividad.

El neorromanticismo buscará así una síntesis entre lo real-objetivo y lo lírico-subjetivo. Lo real-objetivo fijará su atención prioritaria en los problemas sociales y denunciará, sobre todo, los abusos de la burguesía y la incapacidad del sistema capitalista para satisfacer las esperanzas de los proletarios. Lo lírico-subjetivo proyectará esta realidad objetiva al terreno de la idealización, por medio de una interpretación simbólica y poética de los hechos. Esta es la idea básica del nuevo romanticismo: conseguir un equilibrio armónico entre "las dos fuerzas, las del cerebro y las del corazón" $(N R, 76)$. En definitiva, lo que se persigue es conjugar artísticamente los principios de "verdad y belleza" con el fin de lograr "una comunicación del alma del artista, sensible e intuitiva, con el alma del prójimo, con el latido ingente del universo que es la cualidad que la hace inmortal" $(N R, 84)$.

Teniendo presentes estos principios estéticos por los que aboga el nuevo romanticismo, sería oportuno analizar ahora el modo en que Sender se hace eco de ellos y los traduce artísticamente en Las tres sorores.

Las tres sorores puede considerarse la última versión modificada de Siete domingos rojos en la que Sender, además de cambiar el título, ha introducido una segunda trama, ha remodelado el nombre de algunos de los personajes y ha variado asimismo el desenlace final. Sin embargo, a pesar de estos cambios y de los más de cuarenta años transcurridos entre ambas publicaciones, en Las tres sorores Sender sigue manteniéndose fiel a los criterios de la novela social y, en particular, a las tesis del nuevo romanticismo.

El presente ficticio en el que se desarrolla la acción principal de la novela transcurre en la España de 1931. Lucas Samar, el protagonista, es un joven intelectual que llega a Madrid durante la Segunda República, se une al grupo anarquista Espartaco — al igual que haría Sender_ y combina sus actividades revolucionarias con sus estudios de cuarto curso de Filosofía y Letras. Como tarea académica, a Samar se le pide que investigue un manuscrito 
redactado por un visitador de Felipe II, donde se describe el caso de tres monjas aragonesas (Ana, Clara y Pilar) que, al negarse a mantener relaciones sexuales con un clérigo y tres hidalgos, fueron asesinadas a manos de su propia congregación. La curiosidad que despierta en Samar el minucioso informe de Gómez Laín ——conocido como el legajo de Simancas_ - se ve acrecentado por el hecho fortuito de que Las Tres Sorores es también el nombre que reciben tres picos pirenaicos situados en el valle del Bielsa, lugar de nacimiento del protagonista.

Basándose en el presente anarquista, en el análisis del pasado (que se remonta hasta el legendario Espartaco clásico) y en la información que le proporciona el manuscrito sobre las tres sorores, Samar desarrolla una teoría. El protagonista cree que a través de la historia siempre ha existido en el hombre una ley pendular que lo empuja irremisiblemente hacia "la anarquía o la teocracia ejercida despóticamente". 3 Siendo imposible reconciliar armónicamente estas dos tendencias en el terreno político, el único campo en el que se ha hecho posible esta simbiosis ha sido en la ficción: "lástima que la síntesis que hemos sabido hacer en la literatura desde el Arcipreste hasta hoy no sepamos hacerla en política" (201). Como novela de tesis que es, Las tres sorores ejemplificará literariamente esta teoría de Samar.

En Las tres sorores los sucesos de la ficción son narrados por Sender (extrautor), Gómez Laín (intrautor), Samar y los demás personajes. Desde el primer capítulo se presenta ya esta intrincada combinación de puntos de vista. La narración se abre en tercera persona, donde una voz impersonal y omnisciente introduce a Samar y a los siete componentes del grupo Espartaco. Con el uso de este punto de vista, Sender consigue un distanciamiento artístico que le permite caracterizar a los personajes objetivamente y situarlos en un ambiente determinado:

Había también en el grupo un obrero sin trabajo que hacía chapuzas ocasionales (así decía él) llamado Torres y que había sido expulsado del sindicato socialista (socialdemócrata), y un pequeño burgués rubio y poco musculado, llamado Lemus, que trabajaba en una oficina del Estado. (16)

Sin embargo, en este mismo capítulo, el extrautor también se inmiscuye en la ficción en primera persona: "Yo nunca he creído en lo que veía en mi espejo y probablemente a Samar y a otras muchas personas les sucede lo mismo" (25); e incluso se dirige expresamente al lector: "No vale la pena explicarla [la diferencia], porque el lector lo deducirá por sí mismo" (21). Con este doble enfoque narrativo, Sender se sitúa simultáneamente en dos planos espacio-temporales: el del lector y el de los acontecimientos narrados.

Gómez Laín, como supuesto responsable de la autoría del legajo de Simancas, funciona en la ficción como intrautor del relato de las monjas bernardas. Su irrupción en la novela es indirecta y a través de la consabida técnica del manuscrito. La perspectiva que ofrece este intrautor es siempre mediante el empleo de la primera persona narrativa, al ser testigo de la

\footnotetext{
${ }^{3}$ R.J. Sender, Las tres sorores (Barcelona: Destino, 1974) 8. De ahora en adelante, las citas referidas a esta novela aparecen en el texto entre paréntesis y seguidas por el número de página.
} 
acción secundaria. Dado que su tarea consiste en redactar un informe oficial para Felipe II, su visión pretende ser objetiva y todo lo que relata aparece entrecomillado. Sin embargo, ocasionalmente, Gómez Laín se deja llevar por su inevitable subjetivismo e introduce algún que otro comentario personal, como cuando exclama en relación a las tres sorores: “iQue grande ejemplo para todas las mujeres de nuestro siglo y de los siglos venideros!" (252).

Para conectar temática y técnicamente el mundo del anarquismo con el del misticismo, Sender se sirve del doble papel que desempeña Samar como activista del grupo Espartaco y, a la vez, como lector del manuscrito de Gómez Laín. Esta duplicidad le permite exteriorizar los problemas vinculados con el anarquismo, y conectarlos interiormente — como lector_— con su dimensión mística. Aunque Samar funciona como personaje colectivo o representativo del grupo Espartaco, Sender también permite que los demás personajes se manifiesten y actúen por sí mismos. Como señala Michico Nonoyama, a medida que la narración avanza, los personajes van adquiriendo más soltura, "muestran sus intenciones y las motivaciones de sus acciones y otros se encargan de comentar los resultados". ${ }^{4} \mathrm{La}$ voz del extrautor en primera persona va diluyéndose paulatinamente con este desarrollo, mientras que Samar y los otros personajes van ocupando el centro de la acción. Esto no significa que Sender deje por entero la narración en manos de los personajes. Su presencia sigue sintiéndose por medio de frases del tipo "ya dije", "como se verá más tarde", etc. Pero estas intromisiones van haciéndose más esporádicas y se les va concediendo un mayor terreno a las intervenciones dialogadas y analíticas de los personajes, así como al relato de las monjas bernardas.

Samar termina la lectura del manuscrito ya casi al final de la novela. A partir de aquí, la acción se desplaza hacia el intento de liberar a los camaradas que se encuentran en la cárcel Modelo. Esta información nos la proporciona un viejo anarquista que, a manera de informe, nos hace saber que la intentona ha fracasado y que no ha sido posible "llevar la luz de la esperanza a los pechos de los camaradas encarcelados" (303). Una vez acabado este informe, Sender — como autor omnisciente_— retoma la palabra y pone punto final a la novela con una pincelada lírica: "Era la primavera y las acacias de las calles mostraban sus racimos color violeta. Olía bien" (309). De este modo, el extrautor cierra parentéticamente la ficción haciendo uso del mismo enfoque narrativo con el que la comenzó.

En una novela como Las tres sorores la ideología que profesa el autor salta inmediatamente a la vista. Sender es un novelista comprometido con el movimiento anarquista y, lógicamente, sus ideas políticas se reflejan en el texto. En Las tres sorores esta ideología se concreta en la crítica directa o irónica hacia el comunismo y los valores y modos de vida burgueses. En la novela la crítica a los comunistas es implacable y responde a un verdadero sentimiento de odio que existió por parte de los anarquistas. Al comunismo se le recrimina su aburguesamiento: "vio a un señorito con la hoz y el martillo bordados en seda sobre su camisa" (70); su pseudointelectualismo, "que generalmente cubría una ignorancia pedante y fatua" (69); así como su crueldad: "en Rusia todo lo hacen a fuerza de

\footnotetext{
${ }^{4}$ M. Nonoyama, El anarquismo en las obras de R.J. Sender (Madrid: Playor, 1979) 129.
} 
aparatnik, o sea, de garrotazo y tente tieso" (197). La sociedad burguesa es también objeto de duros atagues: "mi padre ha muerto porque su misión era morir y la de la burguesía matarlo" "(83). A veces, la crítica no es tan general y hay un ataque directo hacia los diferentes estamentos de la sociedad: “¿No sabéis que esta mañana matásteis a tres compañeros nuestros? Has sido tú, el comerciante, y tú, el cura, y usted, señor juez, y usted, damisela de faldita tu-tú" (77). También hay una severa crítica contra el gobierno republicano y su oportunismo, pues "el giro que el gobierno da a las cosas es tan ingenioso ... que dan ganas de hacerse republicano y burgués" (127).

Toda la crítica social que se desprende de la novela evidencia que el estado de cosas que en ella se narran le afecta tan profundamente a Sender que no puede mantenerse neutral. Para Pablo Gil Casado, esta posición ideológica del autor hace que su narrativa se convierta frecuentemente en "apología de una tendencia". ${ }^{5}$ En todo caso, esta opinión no invalida el hecho de que Las tres sorores sea una obra de indiscutible valor artístico. Lo que ocurre es que Sender, siguiendo las ideas del nuevo romanticismo, intenta reconciliar política y arte en la ficción. Algo que consigue plenamente, ya que el tema que mejor definiría la novela sería la anarquía como creación literaria.

La novela quiere reflejar unos acontecimientos históricos que en aras de la verosimilitud precisan un enfoque objetivo. Sin embargo, esto es simplemente el punto de partida. Una vez expuestos los hechos sociológicos y políticos que van a enmarcar el desarrollo narrativo, Sender se lanza a explorar la repercusión de lo exterior-objetivo en lo interiorsubjetivo a través de una serie de recursos estilísticos.

De acuerdo con la estética del nuevo romanticismo, Sender interpreta la realidad cotidiana por medio de los símbolos. Al igual que en Siete domingos rojos, la estructura sobre la que se sustenta Las tres sorores responde al mito de la "Creación y el Triunfo del anarcosindicalismo" (Gil Casado, 314). Al hojear un calendario, Leoncio Villacampa uno de los activistas__ encuentra siete domingos consecutivos marcados en tinta roja. Este incidente situará la acción de la novela en un plano alegórico o simbólico. Del mismo modo que Dios creó el mundo en siete días, la acción desarrollará las actividades del grupo Espartaco durante siete domingos. Durante este tiempo simbólico se luchará por la creación de un mundo diferente del burgués. La lucha por la consecución de este nuevo mundo será lo que le dé cuerpo al desarrollo narrativo de la novela.

Los personajes también están caracterizados simbólicamente. Elvira, la novia de Samar, cuyo nombre "quiere decir en árabe 'el desierto"” (38), simboliza lo estático, lo conformista, lo burgués. Star García, por el contrario, representa el inconformismo revolucionario. El carácter ambivalente de esta adolescente de quince años, que juega con muñecas y pistolas, se evidencia también en el hecho de tener varios nombres: "para ti __le dijo a Samar_— soy la Chika, para Leoncio soy Star y para mi abuela Evangelina. O Eva” (81). Su dinamismo se expresa igualmente por medio del gesto simbólico y habitual de cambiar de

5 P. Gil Casado, La novela social española (1920-1971) (Barcelona: Seix Barral, 1975) 65. 
jersey, pues "desde que comenzaron los sucesos la Chika iba poniéndose un jersey de diferente color cada día" (186).

Para plasmar la dimensión metafísica del anarquismo, Sender recurre también a una serie de símbolos simples y sostenidos. Así, el "misticismo" de uno de los miembros anarquistas se simboliza por medio de su larga y "apostólica" melena blanca. La tía Isabela está siempre asociada en la novela con dos objetos: el rosario y la granada de piña. La proyección mística del anarquismo se aprecia asimismo en Emilia, personaje que después de participar en un sabotaje va a la iglesia a confesarse. A nivel sostenido, esta misma tendencia místico-libertaria se manifiesta en las monjas bernardas, que oscilan ambivalentemente entre la religión y el caos orgiástico.

El carácter de los personajes está íntimamente relacionado con el espacio que habitan. Los espacios abiertos están asociados a los deseos instintivos, sensuales y liberadores de los personajes. En este medio se hallan a sus anchas Samar, Star o Emilia. Los espacios cerrados (como el convento de las bernardas, el cuartel donde vive Elvira y la cárcel) están asociados a la represión y frustración de los que se mueven en él. A veces, el valor simbólico de estos espacios se proyecta sobre algún personaje por medio de un detalle significativo. Así, el anarquista Germinal siempre deja su casa abierta como reflejo simbólico de sus ansias de libertad.

La naturaleza también va a encarnar distintos valores simbólicos. Así, por ejemplo, el campo simboliza la anarquía; las montañas en las que están enclavadas Las Tres Sorores, el misterioso misticismo de las monjas bernardas; el sol, las fuerzas vivas de la revolución; la primavera, la esperanza de un futuro mejor, etc. A través de esta deformación simbólica, Sender consigue elevar poéticamente la realidad cotidiana. Sin embargo, al escritor también le interesa avalar la autenticidad y verosimilitud de los hechos que se narran, y para ello recurre a menudo a detalles históricos y documentales. En este sentido, las huelgas, los sabotajes y la prohibición del derecho de reunión que se mencionan en la novela, se ajustan fielmente a la realidad de la época. Asimismo, el mitin en el Teatro Paraninfo podría muy bien ser el que se celebró en 1931 en el Teatro Conservatorio de Madrid. Sender también gana verosimilitud describiendo la localización exacta de los lugares y nombrando a personajes históricos como Cánovas del Castillo, Maura o el propio Manuel Azaña, que llega incluso a hablar con el camarada Leoncio Villacampa. Asimismo, el legajo de Simancas, al presentarse como documento histórico, también le confiere historicidad — por asociación—— a la acción principal.

Para Díaz Fernández todo arte implica un estilo. Pero hace una matización cuando afirma que éste "debe ir de acuerdo con las formas vitales que constituyen la órbita social donde nos movemos" $(N R, 81)$. En Las tres sorores Sender también hará lo propio y ajustará su estilo literario a las dos "órbitas sociales" que presenta en la novela.

En líneas generales, la acción principal se caracteriza por la construcción de oraciones simples y la gran abundancia de verbos (con frecuencia antepuestos a los sujetos) que proporcionan rapidez y dinamismo a la prosa. Igualmente, se le concede más importancia a 
los sustantivos que a los adjetivos porque, en opinión de Sender, "la abundancia de adjetivos es pobreza de expresión". ${ }^{6} \mathrm{El}$ escritor se servirá de este estilo abrupto y directo para reflejar el ambiente de turbulencia social que vive España en los años treinta:

Corretean los caballos, uno resbala y casi cae, arrancando chispas al suelo. Y vuelven los tiros, algunos aislados, aquí y allá, dos o tres bloques más lejos del teatro. Llega otro camión de fuerzas armadas y en pocos minutos las calles quedan despejadas y en silencio. Hay heridos que huyen o que se dejan meter en ambulancias. Pero han quedado sobre el pavimento tres muertos. (63)

En oposición a este estilo literario, la acción secundaria de las monjas bernardas se caracteriza por la subordinación, el uso del polisíndeton y la afectación expresiva:

Lo que sucedía era que el escándalo era de proporciones tan magnas y desacostumbradas que nadie quería hacerse cargo de que existía y comprendían todavía algunas personas que la naturaleza es poderosa y la moral flaca y que por ser monjas no estaban menos sujetas a la esclavitud de la carne, que fuerte es y todos lo sabemos por propia experiencia. (254)

La artificiosidad lingüística empleada por Gómez Laín se ajusta al estilo barroco y perifrástico del siglo XVI y contrasta con el estilo directo utilizado en la acción principal. Sin embargo, ambos estilos literarios, aún siendo diametralmente opuestos, refuerzan la verosimilitud de la novela. Ahora bien, con la intención de imprimirle a la obra un tono poético que compense el realismo de estos dos estilos, Sender utilizará una gran variedad de recursos estilísticos. De entre ellos, la personificación y el símil son quizás los más importantes: "La mañana era femenina, rubia como ella, alta y de una delgadez sazonada. Azul de ojos —_inmensa de luz__ como ella, y tierna y dulce con sus brazos frescos" (99). Hay también ejemplos de paranomasia ("préstame tu revolver — para revolverme"); sinestesias ("el grupo fue deshaciéndose en murmullos hacia el interior"); anáforas ("era toda la vida. La vida entera. La vida entera de cada ser humano"); y alguna que otra greguería ("aquel ombligo es el timbre de alarma del paisaje").

Junto a estos procedimientos retóricos, hay en la novela un intento de creación lingüística. Así, Sender incorpora dentro de la narración poemas enteros en francés o vocablos en lengua inglesa, que distorsionan la estructura unívoca. El escritor también experimenta con el valor expresivo de los neologismos ("sofrosine cervical", "deliquio glandulatorio" "baladón, baladón gafa chiviri, chiviri macá) y con el entreguionado de términos en cadena ("filosófico-cínico-lírico-místico-criminal-sensual”) que le permite condensar conceptos de forma aglutinadora.

En Las tres sorores la prosa es más pictórica que musical, sin duda por la enorme afición que siẻmpre sintió Sender por la pintura. El color que predomina en la novela es el gris, lo cual hace que su prosa sea más bien oscura:

Gris — de los muros-, negro, de los hábitos y las sombras de la capilla en la que siempre era de noche y el blanco almidonado de las tocas. Es verdad que esa combinación de colores (blanco, negro y gris) es una de las más nobles y solemnes. Negro, blanco y

\footnotetext{
${ }^{6}$ Citado por M. Peñuelas, Conversaciones con R.J. Sender (Madrid: Magisterio Español, 1970) 237.
} 
gris bien combinados, eran los colores del Nuevo Testamento, con excepción del Evangelio de San Juan, que tiene colores y volutas y espirales graciosos y terribles. (29)

El autor evita los colores fuertes. No le gusta el rojo, y cuando lo emplea es para expresar situaciones desagradables y hacer resaltar los tonos fríos o neutros. Aunque Sender no concibe el color como un fin en sí mismo, el colorido de su prosa trasciende lo estrictamente ambiental y adquiere, junto a las sensaciones, una dimensión lírica.

En la novela hay varios tipos de percepciones sensoriales, pero predominan las visuales, las auditivas y las de movimiento. Las primeras están en íntima relación con la proyección de la luz sobre superficies de tonos neutros: "el agua se oscurece en la orilla, luego tiene una cenefa blanca y después en el último nivel sobre la tierra es incolora y transparente" (102). Las sensaciones auditivas también tienen su importancia y son generalmente producidas por ruidos metálicos (campanas, silbidos de tren, etc.) o mecanizados (como en el caso de los altavoces que transforman la voz humana). La sensación de silencio también está asociada a lo sensorial auditivo al contrastar con todos los demás tipos de ruidos y sonidos. Los silencios que plasma Sender en la novela se oyen y se hacen elocuentes, como cuando se nos dice que "Samar contesta con un silencio vergonzante" (178). Por último, la sensación de movimiento se transmite a través de la consistente brevedad de oraciones, la abundancia de verbos y el estilo directo que caracteriza a la acción principal. También contribuye a crear este efecto el sucesivo cambio de enfoques, semejante al travelling cinematográfico:

El teatro de barrio estaba en una calle amplia por donde corrían los tranvías y autobuses. Los cerveceros sacaban a la acera su espuma en vidrio tallado. Junto a la esquina que se desdoblaba en una plazuela había tres vendedores. Una vieja ofrecía pastillas de jabón sobre una pequeña tabla colgada del pecho. El teatro estaba un poco más arriba, con la primera planta confundida entre los árboles. (51)

A modo de conclusión, podemos decir que Las tres sorores expresa admirablemente las inquietudes estéticas y sociales del nuevo romanticismo. Siguiendo los criterios de Díaz Fernández, Sender evita un análisis interpretativo de la realidad exclusivamente en base a hechos históricos objetivos. Esto le imposibilitaría la proyección humana al terreno de la idealización, que el nuevo romanticismo siente como una necesidad. Del mismo modo, tampoco quiere el autor dejarse llevar por un subjetivismo extremado, que es justamente lo que el neorromanticismo le critica a los escritores orteguistas. Para Sender, entonces, el único medio válido para denunciar, transformar y crear simultáneamente una obra de verdadero valor literario pasa ineludiblemente por la necesidad de reconciliar orgánicamente los principios neorrománticos de "verdad y belleza", en fundir armónicamente compromiso y arte. Es precisamente en esta doble visión que propugna el nuevo romanticismo, y siempre presente en Las tres sorores, donde reside el mayor acierto de Ramón J. Sender. 
